\title{
Ásia Central e seus desafios geoeconômicos perante o COVID-19
}

Ásia Central e seus desafios geoeconômicos perante o COVID-19

L'Asie centrale et ses défis géoéconomiques face au COVID-19

Central Asia and its geoeconomic challenges face to COVID-19

Asia Central y sus desafíos geoeconómicos ante COVID-19

\section{Jonathan Christian Dias dos Santos}

\section{(Q) OpenEdition}

\section{Journals}

Edição electrónica

URL: https://journals.openedition.org/espacoeconomia/11821

DOI: 10.4000/espacoeconomia. 11821

ISSN: 2317-7837

\section{Editora}

Núcleo de Pesquisa Espaço \& Economia

\section{Refêrencia eletrónica}

Jonathan Christian Dias dos Santos, «Ásia Central e seus desafios geoeconômicos perante o COVID-19», Espaço e Economia [Online], 18 | 2020, posto online no dia 17 abril 2020, consultado o 21 setembro 2021. URL: http://journals.openedition.org/espacoeconomia/11821 ; DOI: https://doi.org/ 10.4000/espacoeconomia.11821

Este documento foi criado de forma automática no dia 21 setembro 2021.

\section{(c) (i) (2)}

Espaço e Economia - Revista brasileira de geografia econômica est mise à disposition selon les termes de la licence Creative Commons Attribution - Pas d'Utilisation Commerciale - Partage dans les Mêmes Conditions 4.0 International. 


\title{
Ásia Central e seus desafios geoeconômicos perante o COVID-19
}

\author{
Ásia Central e seus desafios geoeconômicos perante o COVID-19 \\ L'Asie centrale et ses défis géoéconomiques face au COVID-19 \\ Central Asia and its geoeconomic challenges face to COVID-19 \\ Asia Central y sus desafíos geoeconómicos ante COVID-19
}

Jonathan Christian Dias dos Santos

Agradeço ao professor André Santos da Rocha (PPGGEO/UFRRJ) pelas contribuições ao presente texto.

\section{Introdução}

1 O ano de 2020 tem sido movimentado para os estudiosos da geopolítica. Em aproximadamente 90 dias, testemunhamos tensões latentes entre os Estados Unidos da América e o Irã, a guerra Russa-Saudita na produção e desvalorização no preço do petróleo, e mais recentemente, observamos com muita atenção o deslocamento mundial do COVID-19, classificado como pandemia pela Organização Mundial da Saúde (OMS) no dia 11 de março.

2 Como muito bem afirmou o geógrafo Hélio Caetano Farias, em texto recém publicado e intitulado "Geopolítica, respostas nacionais e a pandemia do coronavírus", a expansão do vírus pelo mundo está intrinsicamente ligado ao funcionamento e manutenção do sistema econômico o qual estamos globalmente conectados. o coronavírus deixou de se tratar apenas de uma problemática de saúde pública, tornando-se também uma questão política e econômica internacional (FARIAS, 2020). Ou seja, a pandemia torna-se uma problemática geoeconômica a medida em que afeta o principal instrumento de influência e condução geopolítica do século XXI: a economia (BLACKWILL, WARIS, 2016).

3 Tal impacto da crise no cenário geoeconômico ${ }^{1}$ é grande e a preocupação dos Estados em resguardar suas economias se manifestam de diversos modos: Estados Unidos 
anunciaram um pacote de US\$ 2 trilhões de dólares; França um de $€ 45$ bilhões; Espanha $€ 200$ bilhões de euros, e assim por diante. Como afirmou Bruno Le Maire, ministro da Economia e Finanças da França: "O choque será violento. A guerra econômica e financeira será duradoura"2.

4 Tomando o pensamento exposto nos parágrafos anteriores como fio condutor desta reflexão, podemos compreender que a atual pandemia que assola o mundo é mais uma das crises sistemáticas que o capitalismo tem produzido ciclicamente ao longo de sua história, sobretudo no mundo globalizado, como afirmava Milton Santos (1999). E este recente desafio de ordem biológica-econômica-política mundial afetará de modo significativo os códigos geopolíticos dos atores globais: i) concorrência na esfera científica-tecnológica entre os países (quem primeiro conseguirá obter uma possível preparação biológica que contenha o SARS-CoV-2, disputa por equipamentos hospitalares); ii) acirramento na projeção de poder por meio da cooperação internacional; iii) quem irá liderar uma possível nova lógica de organização geoeconômica pós-pandemia?

5 Tais questões certamente levarão tempo para serem respondidas, mas as avarias deste momento de instabilidade são atuais e diárias. Atentamente vemos as rupturas que estes estragos têm produzido socialmente mundo afora, a exemplo de Itália, Espanha e EUA que nas últimas semanas produziram e sentiram uma catástrofe nacional, com milhares de mortos em seus territórios.

6 O vírus sendo carregado no fluxo de circulação global por meio da intensa cadeia de transportes que conectam os mais distantes espaços do mundo, e promovidos pelo capitalismo por meio da remoção de barreiras, isto é, a compressão do espaço para a possibilidade de exploração de outros territórios (HARVEY, 1992), sem demora, alcançou o espaço centro-asiático. Nos parágrafos seguintes demonstraremos os possíveis impactos geoeconômicos que podem ocorrer como resultado do COVID-19 na Ásia Central.

\section{3 de março: o primeiro caso no Cazaquistão e amplificação do vírus no espaço centro-asiático}

7 Apesar de 3 dos 5 países centro-asiáticos fazerem fronteira com a China, epicentro primário da doença, somente no dia 13 de março de 2020, o primeiro caso do novo coronavírus oficialmente surgiu na Ásia Central: um cazaque recém chegado da Alemanha, testou positivo para a doença ${ }^{3}$. Desde então, os casos se multiplicaram, seguido por confirmações de infectados também no Uzbequistão ${ }^{4} \mathrm{e}$ no Quirguistão ${ }^{5}$. A representante da OMS para o Tajiquistão, Galina Perfilyeva, declarou que até o começo do mês de abril Tajiquistão e Turcomenistão não possuem casos positivos para COVID-196. 


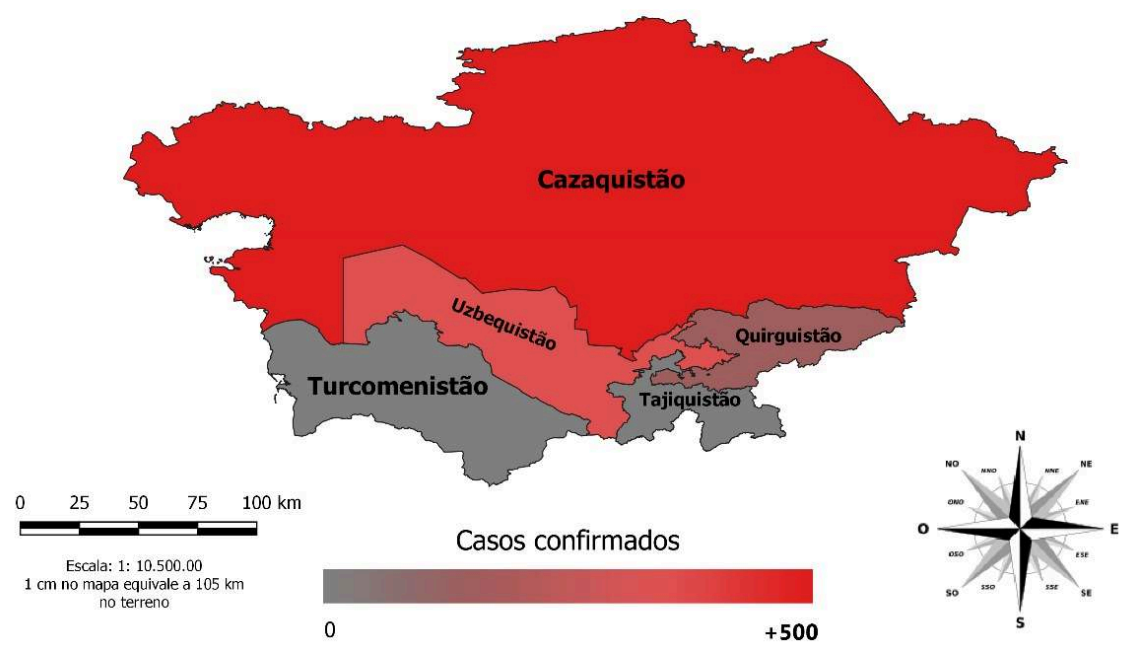

FIGURA 1 - Média geral de casos do COVID-19 confirmado nos países da Ásia Central até o dia 05 de abril de 2020 - 12:54 GMT

Fonte: Elaboração do autor com dados do Coronavirus COVID-19 Global Cases. John Hopkins University \& Medicine. Disponível em: https://coronavirus.jhu.edu/map.html

8 As medidas tomadas por estes dois últimos países citados no parágrafo anterior foram: a restrição ao ingresso de estrangeiros em seus territórios, controle sobre a circulação nos centros urbanos e a repatriação daqueles que estivessem fora do país. Até o dia 31 de março, o Tajiquistão havia posto em quarentena 6.222 pessoas que chegaram ao país, segundo o Ministério da Saúde tadjique ${ }^{7}$, enquanto o Turcomenistão tem realizado voos especiais para o retorno de cidadãos que estejam no exterior8. Já o Cazaquistão, Uzbequistão e Quirguistão encontram-se em estado de emergência. As atualizações sobre o número de casos nos países são feitas via TV e internet. Até o dia 05 de abril, nove mortes por coronavírus foram registradas na Ásia Central: 6 no Cazaquistão, 2 no Uzbequistão e 1 no Quirguistão. 


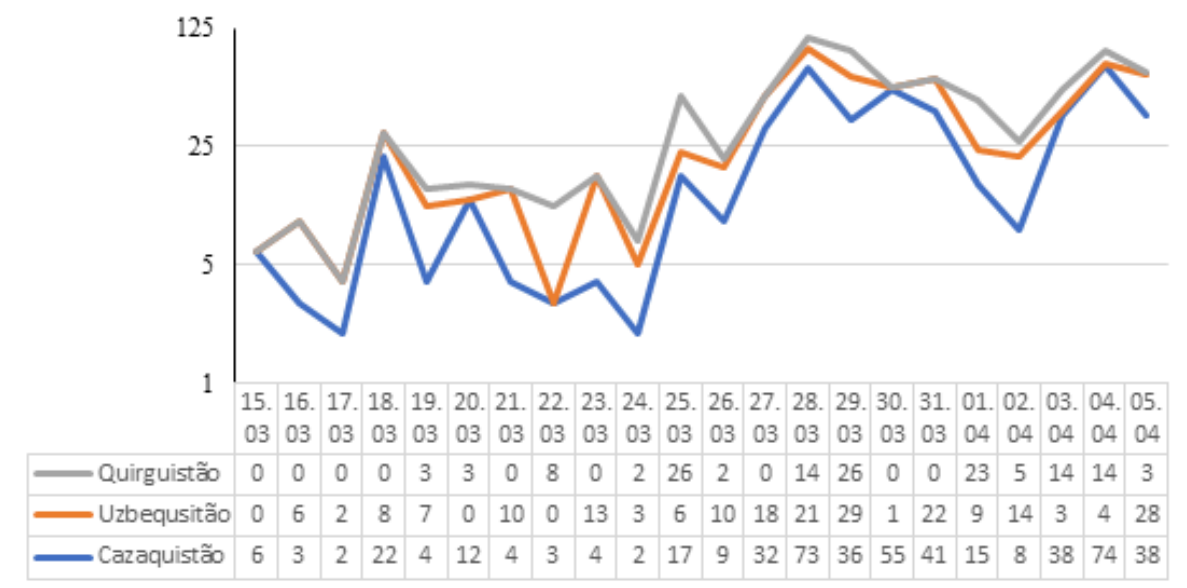

Fonte: Situation update worldwide, as of 5 April 2020. European Centre for Disease Prevention and Control (ECDC) - 12:54 GMT, Ministério da Saúde do Uzbequistão, Ministério da Saúde do Quirguistão, Ministério da Saúde do Cazaquistão

\section{Encerramento das fronteiras e o rompimento no fluxo migratório}

Para a Ásia Central, o coronavírus, assim como para todo o resto do mundo, representa um perigo social e econômico. Com as crises (econômicas e políticas) ao longo dos anos 90, que afetaram os recém criados estados centro-asiáticos, cidadãos destes países migaram para outras partes do mundo, sobretudo para a Rússia e para o espaço da Comunidade dos Estados Independentes (CEI), na busca pelo emprego e melhores condições de vida para si e para os seus descendentes que permaneceram na terra natal. Este movimento migratório impactou não apenas socialmente, mas também economicamente os países da Ásia Central (LAURELLE, 2007). Segundo dados do Federal Security Service (FSB) até a primeira metade de 2019, das cinco maiores nacionalidades de origem dos trabalhadores imigrantes na Rússia, quatro eram da Ásia Central: Uzbeques, Tadjiques, Quirguizes e Cazaques ${ }^{9}$. 
Gráfico 2 - Cinco maiores nacionalidades de origem dos trabalhadores imigrantes na Rússia durante a primeira metade de 2019

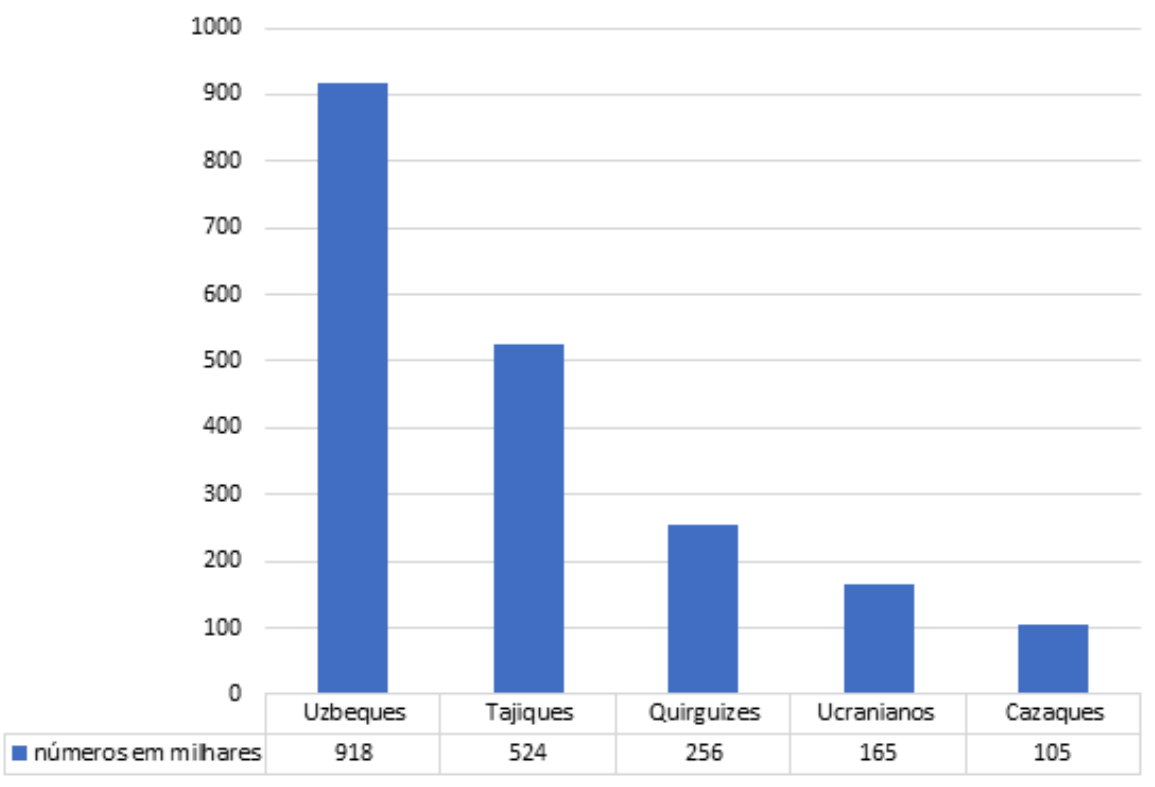

Tabela adaptada do The Moscow Times com dados do FSB

10 Este intenso fluxo migratório entre as populações centro-asiáticas tendo como o seu principal destino o antigo espaço soviético, ou mais especificamente a Rússia, ocorre por uma questão de laços sociais entre os territórios de saída/chegada do imigrante. Segundo Vale, Saquet e Santos (2005, p.22-23) citando Masey (1990) "tais laços unem migrantes e não-migrantes em uma complexa teia de papéis sociais complementares e relacionamentos interpessoais que são mantidos por um quadro informal de expectativas mútuas e comportamentos predeterminados."

O World Migration Report 2020, desenvolvido pela Organização Internacional para as Migrações (OIM), uma agência da Organização das Nações Unidas (ONU), aponta que em 2018, o Quirguistão e o Tajiquistão figuravam entre os cinco primeiros países em que as remessas enviadas por seus cidadãos em terras estrangeiras desenvolvendo atividades laborais, compuseram parte do produto interno bruto (PIB).

A diáspora tadjique começou com a Guerra Civil que assolou o país entre 1992-1996. No cenário pós-guerra, foi severa a crise socioeconômica que recaiu sobre o território. Em 1998, por exemplo, estima-se que cerca de $80-90 \%$ da população encontravam-se em situação de pobreza ${ }^{10}$. Com o intenso fluxo de pessoas se retirando do país, em busca de trabalho em outros países (especialmente no antigo espaço soviético, pelos laços sociais-territoriais), e a falta de mão de obra internamente, o Tajiquistão tornou-se cada vez mais dependente daqueles que imigravam. No começo dos anos 2000, por exemplo, o país obteve uma significativa redução da sua pobreza por meio da repatriação de divisas (DANZER; IVASCHENKO, 2010). Nos seis primeiros meses de 2019, foram US $\$ 1.111$ bilhões de dólares transferidos da Rússia para o Tajiquistão, segundo apontou o banco central russo ${ }^{11}$, sendo grande parte desse valor representado pelas remessas enviadas ao país de destino. Com esta relação direta entre países, por meio da força de trabalho, o Tajiquistão, que é o país mais pobre da Ásia Central, consequentemente é afetado por crises transnacionais, como foi em 2013 e 2014 com a crise econômica da 
Rússia $^{12}$, da mesma maneira que deverá sofrer impactos oriundos das recentes disputas entre Rússia e os países da OPEP (assim como o Cazaquistão) e pela crise geoeconômica resultante do coronavírus na China, Irã e outros.

13 A mancha geográfica e a quantidade de cidadãos que servem como força de trabalho no exterior, por exemplo este ano, possivelmente serão contraídas pela oclusão da fronteiriça russa a estrangeiros, devido ao COVID-19. Consequentemente, isso irá gerar o acometimento da repatriação monetária e do produto interno bruto do país, esferas que como apontamos anteriormente, são altamente conectadas. $O$ fechamento entre fronteiras (Tajiquistão - China) também representa um problema para o abastecimento de algumas cidades $^{13}$ e o aumento no valor de produtos primários. Além disso, a resposta que os seus parceiros econômicos (Cazaquistão, China, Rússia, Índia) darão ao vírus será importante para balança comercial do país, que em 2019 fechou com um déficit de US\$184.70 milhões de dólares ${ }^{14}$.

o Quirguistão por sua vez, teve o seu fluxo migratório mais intenso devido as reformas econômicas e a inserção do país na economia de mercado (AKMOLDEV; BUDAICHIEVA, 2012). Durante a década de 1990, enquanto atingia taxas inflacionárias exorbitantes e com o setor industrial em queda (RASHID, 2002), o país enfrentou grave crise econômica, ao mesmo tempo em que, as condições de vida da população também diminuíam significativamente. Foi a partir deste período que o Quirguistão se aproximou de organismos internacionais como o Fundo Monetário Internacional (FMI) e a Organização Mundial do Comércio (OMC), buscando uma saída para sua crise. A migração dos quirguizes para outros territórios também foi reforçada pelas revoluções de 2005 (Revolução das Tulipas) e 2010, ambas ocasionadas pelas escaladas de tensão política e problemas econômicos vividos pelo país durante o final do século XX e os primeiros anos do século XXI. Em 2019, o banco central do Quirguistão apontou que naquele ano foram transferidos $\$ 220.4$ milhões de dólares para o país, dos quais $90 \%$ tinham como país de origem a Rússia, e em segundo lugar os Estados Unidos ${ }^{15}$. $O$ envio de remessas tendo como as duas principais fontes de origens Rússia e EUA se mantém pelo menos a 15 anos, segundo dados do Banco de Desenvolvimento Asiático ${ }^{16}$.

Assim como o seu vizinho Tajiquistão, os quirguizes também são dependentes das remessas enviadas por aqueles que imigram como força laboral e também do comércio exterior. Em janeiro de 2020 a balança comercial do país registrou um déficit de US $\$ 255.7$ milhões de dólares ${ }^{17}$.

Apesar disso, o presidente do banco nacional, Tolkunbek Abdygulov, entende que apenas em maio será possível observar os impactos reais do COVID-19 sobre a economia do Quirguistão $0^{18}$. o país solicitou - e teve seu pedido atendido - ao Fundo Monetário Internacional (FMI) US\$120 milhões de dólares para auxiliar no combate à doença ${ }^{19}$. Pediu apoio também aos chineses, com um possível envio de médicos para ajudar no tratamento ao vírus ${ }^{20}$.

17 Todavia os imigrantes quirguizes, que possuem algumas vantagens pelo fato do país de origem ser membro da União Econômica Eurasiática (UEE), encontraram problemas para chegar ao seu destino final e até mesmo para ocupar vagas de trabalhos em outros países, uma vez que boa parte das atividades no setor de comércio, construção civil e transporte, ocupadas por esses sujeitos, estão suspensas. 
Gráfico 3 - Os 5 países que mais recebem remessas do exterior e a porcentagem destas na estrutura do Produto Interno Bruto em 2018

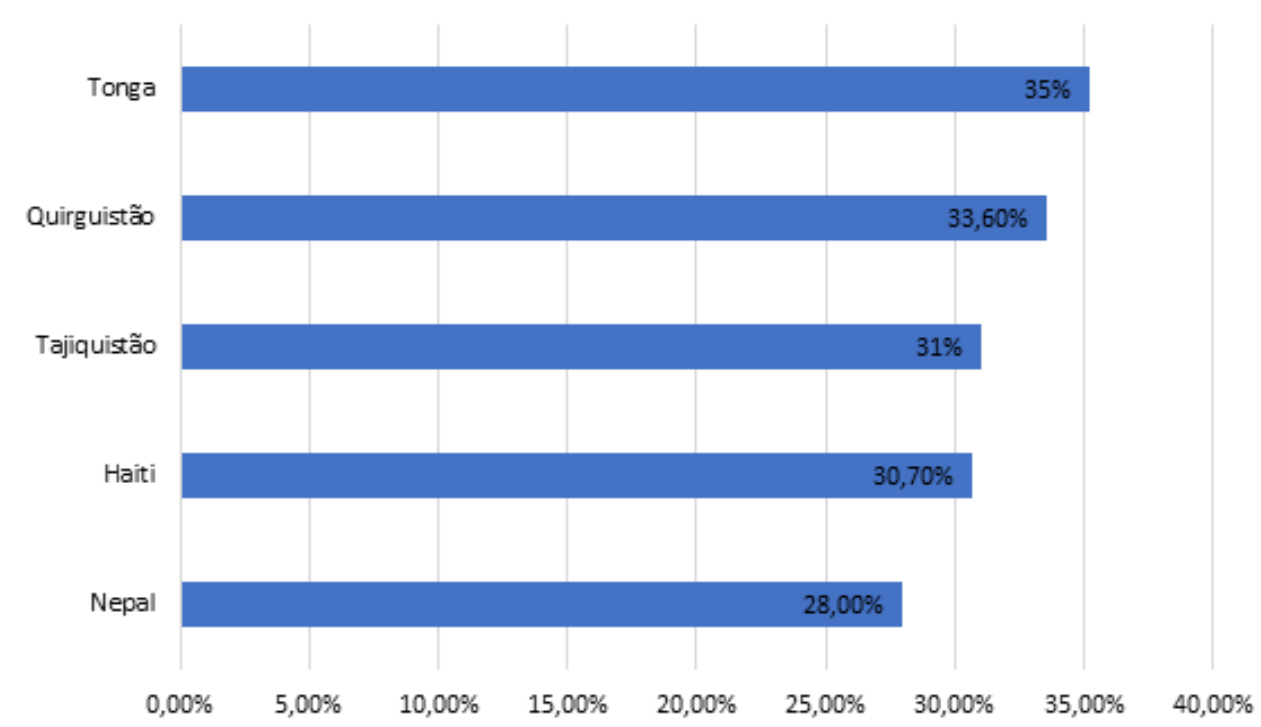

Fonte: World Migration Report 2020

O World Migration Report ainda aponta que o Cazaquistão mantém ativo um dos principais corredores de migrações do continente asiático, em um fluxo intenso de pessoas que se movem em direção a Rússia, e de indivíduos dos Estados vizinhos (Quirguistão, Tajiquistão, Uzbequistão) que chegam ao país em busca de postos de trabalho que exigem baixa qualificação. Outros países que hospedam estes trabalhadores imigrantes em seus mercados laboral são: Turquia, Coreia do Sul e países da Europa Ocidental (World Migration Report, 2020).

O resultado desta dinâmica, que também serviu como ponto de inserção do espaço centro-asiático na lógica econômica local-global, é fruto da apropriação e domínio do espaço por meio da interação entre economia e território, muito bem compreendida pela ótica econômica de Enzo Rullani, em que tal conexão está "em processo constante de expansão" e "ocupa-se de culturas nacionais, de especificidades territoriais e variantes locais ligadas à vida cotidiana" (VALE; SAQUET; SANTOS, 2005, p). Portanto, a supressão das atividades econômicas que estamos acompanhando (redução na circulação de bens e produtos, impedimento no deslocamento migratório e queda no número de vagas de emprego) e mudanças no curso dos fundamentos geoeconômicos, afetarão a vida cotidiana, a dinâmica econômica e as formas territoriais centro-asiáticas as quais foram concebidas ao longo das décadas.

\section{China: ponto de eclosão da pandemia e importante parceiro comercial da Ásia Central}

A crescente presença chinesa na Ásia Central se expressa, sobretudo, por meio Organização para Cooperação de Xangai (OCX), no começo dos anos 2000, e mais recentemente com Belt and Road Iniative (BRI) anunciada em 2013. Em ambas as organizações, que são dois grandes vetores geoeconômicos de Pequim, têm se 
estabelecido fortes laços com os países centro-asiáticos objetivando cooperar em três campos estratégicos: energético, econômico e de defesa.

Como afirma Egler (2007, p.1), "a produção e distribuição de energia é um setor econômico onde os limites entre a geopolítica e a geoeconomia são muito tênues. 0 controle sobre os recursos energéticos e sobre sua distribuição é uma fonte inegável de poder". No campo energético, os Chineses têm investido pesado na construção de gasodutos por todo o território centro-asiático visando a extração de gás natural. Somente em 2019, a PetroChina diz ter transportado 47,9 milhões de metros cúbicos de gás natural pelo gasoduto Ásia Central- China, tendo sido utilizado $80 \%$ da capacidade total da infraestrutura ( 60 bilhões de metros cúbicos por ano) ${ }^{21}$.

Com a extração dos recursos da Ásia Central para utilização em seu gigantesco mercado, a China tem se apresentado como o principal comprador dos recursos de países como o Turcomenistão ${ }^{22}$, por exemplo. Conseguinte desenvolve-se uma dependência energética (JAMALI, 2018) e econômica Sino-Centro-Asiática. Entretanto, tal relação é assimétrica à medida que Pequim possui outras opções de realização de negócio, enquanto a maioria dos países da Ásia Central encontram-se em negócios que os amarram aos chineses. Um exemplo muito evidente deste conflito geoeconômico é o fato de Tajiquistão, Quirguistão, Turcomenistão e Uzbequistão terem parte de seu PIB direcionados para o pagamento de dívidas externas com a China (HORN; HEINHART; TREBESCH, 2019). Essas dívidas muitas vezes são referentes a empréstimos para a construção de infraestruturas que servem para os fins econômicos chineses ${ }^{23}$.

Todavia, a China foi o ponto de eclosão do novo coronavírus, em dezembro de 2019. Desde então o país teve de refrear a sua dinâmica econômica, uma vez que as proporções tomadas pela doença levaram ao isolamento de cidades, paralisação de atividades e o consequente confinamento da população. Sua intensa produção teve uma queda de $13,5 \%$ nos dois primeiros meses do ano, segundo apontou o National Bureau of Statistics of China.

Como consequência, a importação de gás natural por parte da China teve de se readequar a esta realidade. A redução de importação foi anunciada pela Petrochina no dia 5 de março ${ }^{24}$, acendendo um alerta nos países da região. De acordo com o ministro de energia do Cazaquistão, Nurlan Nogyev, a redução, pelo menos no Cazaquistão, seria entre 20 a $25 \%^{25}$. O reflexo desta ação pode ser observado no gasoduto, citado anteriormente, Ásia-Central-China que até março de 2020 havia importado 7 bilhões de metros cúbicos de gás, enquanto no mesmo período, em 2019, importou 11 bilhões de metros cúbicos, conforme mostram dados do divulgados pelo ministério do comércio chinês ${ }^{26}$.

Entretanto, para além das questões energéticas, a interrupção no fluxo das fronteiras centro-asiáticas com a China, pode afetar também outro elemento geoeconômico estratégico: a cadeia logística (EGLER, 2007). Além de estarem conectados com a China via gasodutos, parte dos países da Ásia Central encontram-se como componentes do China, Central Asia, West Asia Economic Corridor ${ }^{27}$, dentro do projeto da BRI. A principal função deste corredor, que é de conectar a China e Ásia Central com parte do continente europeu, é fundamental para o funcionamento do plano geopolítico chinês e para a economia dos países centro-asiático, pois é através dele que se tem grande parte do deslocamento logístico de bens e produtos. 
Os dados de importação e exportação (contabilizando bens, recursos energéticos e afins) entre China e os países da Ásia Central nos dois primeiros meses deste ano, em relação ao mesmo período em 2019, demonstram queda em boa parte deles, expondo um cenário pouco favorável as economias centro-asiáticas. Segundo o General Administration of Customs of the People's Republic of China a balança comercial ficou da seguinte maneira:

TABELA 1 - Exportação / Importação entre China e Ásia Central durante janeiro-fevereiro de 2020

\begin{tabular}{|l|l|l|l|l|}
\hline País & Exportação & Importação & Total & Taxa de Importação (China) \\
\hline Cazaquistão & US\$ 1.315 .621 & US\$ 1.620.474 & US\$ 2.936 .094 & $31.6 \%$ \\
\hline Tajiquistão & US\$ 186.720 & US\$ 12.106 & US\$ 198.826 & $-3.8 \%$ \\
\hline Uzbequistão & US\$ 608.682 & US\$ 223.113 & US\$ 831.795 & $-35.4 \%$ \\
\hline Quirguistão & US\$ 602.156 & US\$ 9.139 & US\$ 611.294 & $-7.7 \%$ \\
\hline Turcomenistão & US\$ 42.468 & US\$ 1.360 .432 & US\$ 1.402 .900 & $-17.2 \%$ \\
\hline
\end{tabular}

Fonte: General Administration of Customs of the People's Republic of China. Disponível em: http:// english.customs.gov.cn/Statics/80d0f985-3280-470a-9655-99d08989f181.html - acesso em 03 abr. 2020.

Além disso, a restruturação espacial e econômica da Ásia Central promovida pela China tem feito emergir um número expressivo de chineses operando negócios nos países da região. Em 2019 por exemplo, o Quirguistão registrava cerca de 400 chineses operando empresas em diversos setores econômicos do país ${ }^{28}$, já o Uzbequistão, em 2018, disse ter 1,500 chineses operando negócios no país ${ }^{29}$. De modo muito objetivo, podemos observar que a integração do espaço centro-asiático à estratégia geopolítica/geoeconômica chinesa encaixa a região na esteira da crise COVID-19, independentemente dos desejos dos governantes locais.

\section{Conclusão}

Concluímos o presente artigo apresentando aquilo que consideramos como os principais desafios geoeconômicos diante da equação do COVID-19 para a região. Se a geoeconomia como aponta Egler (2007, p.5-6) "define as relações espaciais de poder entre domínios e fronteiras, que redesenham constantemente os contornos do mapa do mundo atual", veremos as dinâmicas territoriais-econômicas na Ásia Central sendo redesenhadas pelos principais elementos que constituem a geoeconomia dos países da região: a repatriação monetária, o fluxo migratório e a circulação de mercadorias. Eles se apresentam como uma complexa teia de rudimentos que interligados funcionam de modo a constituírem uma base econômica centro-asiática. Entretanto, a velocidade com que esses fundamentos geoeconômicos refletem sobre a esfera econômica regional seguem a uma urgência exterior, existindo aí os desafios destes em relação a situação global atual. 
Estando na encruzilhada entre China, Rússia e Irã, países com grande quantidade de casos registrados, a região enxerga a necessidade de refrear o avanço do vírus em seus territórios pela dimensão política que eles possuem, dada a concentração de poder existente no seu interior. O objetivo deve ser o da prevenção no aumento dos problemas socioeconômicos já existentes nos países, que podem ser reforçados pelos desafios geoeconômicos, apontados no parágrafo anterior. A instabilidade oriunda de um distúrbio socioeconômico associados aos elementos geoeconômicos centroasiáticos, são capazes de adquirir formas a reconstituir um cenário que reconfiguraram as espacialidades e relações intra e inter-regionais, atingindo principalmente atores como Rússia e China, mas também Índia, Paquistão, Afeganistão e outros.

De modo geral, o COVID-19 apresenta desafios geoeconômicos que colocam os Estados daquele espaço no âmago de questões territoriais-políticas-econômicas a qual associadas às atribulações sociais caracterizam suas relações geopolíticas. Os principais objetivos dos líderes centro-asiáticos hoje devem ser: i) evitar o alargamento de crises sociais e deterioração da qualidade vida, através de programas sociais e de auxílio prestado pelo Estado às populações mais vulneráveis (por exemplo, desempregados ou famílias que dependem das remessas), como tem feito o governo cazaque. Isso reduziria a elevação do grau de tensão na região, que em seu nível extremo poderia eclodir em crises políticas ou étnicas, gerando uma intensificação na fuga de populações e parceiros econômicos; ii) manutenção das relações geopolíticas e de cooperação, colaborando no processo de contenção do vírus e segurança biológica, fornecendo insumos hospitalares, alimentos e afins, o que de modo bastante adequado os países vêm realizando entre si e com seus parceiros exteriores (como fez o Uzbequistão com o Afeganistão, e o Turcomenistão com o Irã), preservando assim a função política e econômica que a região vem desempenhando nos últimos anos.

\section{BIBLIOGRAFIA}

AKMOLDOEV, Kiyalbek \& BUDAICHIEV, Aidai. The Impact of Remittances on Kyrgyzstan Economy. International Conference On Eurasian Economies 2012, 2012. Disponível em: https:// avekon.org/papers/534.pdf - acesso em 03 abr.2020

BLACKWILL, Robert D.; HARRIS, Jennifer M. War by Other Means: Geoeconomics and Statecraf. The Belknap press of Havard University press: Cambridge, 2016.

DANZER; M. Alexander; IVASCHENKO, Oleksiy. Migration patterns in a financial crisis. Migration Letters, v. 7, n. 2, pp. 190 - 202, 2010.

EGLER, C. Energia e conflitos territoriais na América do Sul: uma visão geoeconômica. VII Encontro Nacional da ANPEGE, Niterói, 2007.

FARIAS, Hélio Caetano. Geopolítica, respostas nacionais e a pandemia do coronavírus. Observatório Militar da Praia Vermelha., 2020. Disponível em: http://ompv.eceme.eb.mil.br/ masterpage_assunto.php? 
id=188\&fbclid=IwAR3MHSSEAFFjnFZW2Ysfqkcyq816jJRdNMGUnDUqakBfBU192E4pYjYuKCQ acesso em 28 mar.2020

HARVEY, David. Condição pós-moderna: uma pesquisa sobre as origens da mudança cultural. São Paulo: Loyola (1992 [1989]).

HORN, Sebastian; HEINHART, Carmen M.; TREBESCH, Christohp. China's Overseas Lending. NBER Working Paper, 2019. Disponível em: https://www.nber.org/papers/w26050 - acesso em 29 mar. 2020

INTERNATIONAL ORGANIZATION FOR MIGRATION. World Migration Report 2020. Disponível em: https://publications.iom.int - acesso em 28 mar.2020.

JAMALI, Ahmed Bux. Understanding China's Energy Security in Central Asia. In: NOOR, Muhammad Asif. Belt And Road Initiative (BRI): Five year of achievements. The Diplomatic Insight, 2018.

LARUELLE, Marlène. Central Asian Labor Migrants in Russia: The "Diasporization" of the Central Asian States? China and Eurasia Forum Quarterly, v.5, n. 3, p. 101-119, 2007.

RASHID, Ahmed. El auge del islamismo en Asia Central. Barcelona: Ediciones Penísula. 2002.

SANTOS, Milton. A normalidade da crise. Folha de São Paulo, 1999. Disponível em: https:// www1.folha.uol.com.br/fsp/mais/fs2609199903.htm - acesso em 28 mar.2020

VALE, A. L. F; SAQUET, M. A; SANTOS. R. A. O território: diferentes abordagens e conceito-chave para a compreensão da migração. UNIOESTE: Revista Faz Ciência, 2005. 07.01. p. 11-26.

\section{NOTAS}

1. Entende-se por geoeconomia o "uso da economia como instrumento para promover os interesses e a defesa nacional, e produzir resultados geopolíticos positivos" (BLACKWILL, WARIS, 2016, p.20, tradução nossa).

2. França anuncia ajuda de 45 bilhões de euros para empresas e trabalhadores. EFE Brasil. Disponível em: https://www.efe.com/efe/brasil/portada/fran-a-anuncia-ajuda-de-45-bilh-eseuros-para-empresas-e-trabalhadores/50000237-4198174 - acesso em 29 mar. 2020.

3. Kazakhstan Confirms First Three Coronavirus Cases. U.S. News. Disponível em: https:// www.usnews.com/news/world/articles/2020-03-13/kazakhstan-confirms-first-coronavirus-cases - acesso em 28 mar.2020

4. Uzbekistan confirms first coronavirus case - govt. Reuters. Disponível em: https:// www.reuters.com/article/health-coronavirus-uzbekistan/uzbekistan-confirms-firstcoronavirus-case-govt-idUSL8N2B802F - acesso em 28 mar.2020

5. Kyrgyzstan reports 1st coronavirus cases. Anadolu. Disponível em: https://www.aa.com.tr/en/ asia-pacific/kyrgyzstan-reports-1st-coronavirus-cases/1769954 - acesso em: 28 mar.2020

6. WHO representative in Tajikistan officially declares absence of coronavirus cases in the country. Asia-Plus. Disponível em: https://www.asiaplustj.info/en/news/tajikistan/society/ 20200401/who-representative-in-tajikistan-officially-declares-absence-of-coronavirus-cases-inthe-country - acesso em 02 abr.2020

7. 6222 have been quarantined. Ministry of Health and Social Protection of the Republic of Tajikistan. Disponível em: < http://moh.tj/6222-have-been-quarantined/?lang=en> - acesso em 02 abr. 2020 
8. Turkmenistan brings its citizens back home because of pandemic coronavirus. TDH News Agency. Disponível em: http://tdh.gov.tm/news/en/articles.aspx\&article21915\&cat30 - acesso em 02 abr. 2020

9. Russia's FSB Publishes Foreign Worker Statistics for First Time in 20 Years. The Moscow Times. Disponível em: https://www.themoscowtimes.com/2019/08/16/russias-fsb-publishes-foreignworker-statistics-for-first-time-in-20-years-a66895 - acesso em 29 mar. 2020

10. Tajikistan: Progress and Problems at the Heart of Central Asia. Brookings. Disponível em: https://www.brookings.edu/opinions/tajikistan-progress-and-problems-at-the-heart-of-centralasia/> - acesso em 02 abr. 2020

11. Remittance flows to Tajikistan continue decreasing despite rising labor migration. Asia-Plus. Disponível em: https://asiaplustj.info/en/news/tajikistan/society/20190926/remittance-flowsto-tajikistan-continue-decreasing-despite-rising-labor-migration - acesso em $02 \mathrm{abr} .2020$

12. Dependent on Remittances, Tajikistan's Long-Term Prospects for Economic Growth and Poverty Reduction Remain Dim. Migration Policy Institute. Disponível em: <https:// www.migrationpolicy.org/article/dependent-remittances-tajikistan-prospects-dim-economicgrowth - acesso em 02 abr. 2020

13. How Did Coronavirus Affect Tajikistan? CABAR. Disponível em: https://cabar.asia/en/howdid-coronavirus-affect-tajikistan/- acesso em 03 abr.2020

14. Tajikistan balance of trade. Trading economics. Disponível em: https:// tradingeconomics.com/tajikistan/balance-of-trade - acesso em $02 \mathrm{abr} .2020$

15. Remittances to Kyrgyzstan decrease by $\$ 242.1 \mathrm{mln}$ over the year. $24 \mathrm{~kg}$. Disponível em: https://24.kg/english/

137648_Remittances_to_Kyrgyzstan_decrease_by__2421_mln_over_the_year/ - acesso em 02 abr. 2020

16. Remittances and Poverty in Central Asia and South Caucasus. Asia Development Bank. 2008

17. Kyrgyzstan balance of trade. Trading economics. Disponível em: https:// tradingeconomics.com/kyrgyzstan/balance-of-trade - acesso em 02 abr.2020

18. Impact of coronavirus on economy of Kyrgyzstan to be obvious in May. 24kg. Disponível em: https://24.kg/english/

146177_Impact_of_coronavirus_on_economy_of_Kyrgyzstan_to_be_obvious_in_May/ - acesso em 03 abr. 2020

19. IMF Executive Board Approves a US $\$ 120.9$ Million Disbursement to the Kyrgyz Republic to Address the COVID-19 Pandemic. International Monetary Fund. Disponível em: https:// www.imf.org/en/News/Articles/2020/03/26/pr20115-kyrgyz-republic-imf-executive-boardapproves-disbursement-to-address-covid-19-pandemic - acesso em 03 abr.2020

20. Kyrgyzstan to ask China to send doctors to treat coronavirus patients. AKIpress. Disponível em: https://akipress.com/news: 638171:Kyrgyzstan_to_ask_China_to_send_doctors_to_treat_coronavirus_patients/ - acesso em 03 abr. 2020

21. Central Asia-China gas pipeline transports 47.9 billion cu $m$ in 2019. Netfgaz.ru. Disponível em: https://neftegaz.ru/en/news/Transportation-and-storage/516580-central-asia-china-gaspipeline-transports-47-9-billion-cu-m-in-2019-/ - acesso em 29 mar.2020

22. Central Asian Gas: prospects for the 2020s. The Oxford Institute for Energy Studies, 2020.

23. Tajikistan approves Chinese $\$ 360$ million grant for highways. Eurasianet. Disponível em: https://eurasianet.org/tajikistan-approves-chinese-360-million-grant-for-highways - acesso em 29 mar.2020

24. Petrochina suspends some gas contracts as coronavirus hits demand: sources. Reuters. Disponível em: https://www.reuters.com/article/us-petrochina-gas-exclusive/petrochinasuspends-some-gas-contracts-as-coronavirus-hits-demand-sources-idUSKBN20S10W - acesso em 29 mar. 2020 
25. Central Asia's Force Majeure Fears: Impact of COVID-19 Outbreak on China's Natural Gas Supply Demands. Foreign Policy Research Institute. Disponível em: https://www.fpri.org/article/ 2020/03/central-asias-force-majeure-fears-impact-of-covid-19-outbreak-on-chinas-natural-gassupply-demands/ - acesso em 29 mar. 2020

26. Chinese business briefing: Force majeure. Eurasinet. Disponível em: https://eurasianet.org/ chinese-business-briefing-force-majeure - acesso em 03 abr.2020

27. Os países da Ásia Central que estão englobados neste corredor são: Turcomenistão, Uzbequistão, Tajiquistão e Quirguistão. O Cazaquistão está integrado ao The New Eurasia Land Bridge Economic Corridor.

28. Over 400 joint Chinese enterprises operating in economy of Kyrgyzstan - Transport Ministry. AKIPress. Disponível em: https://akipress.com/news: 620162:Over_400_joint_Chinese_enterprises_operating_in_economy_of_Kyrgyzstan__Transport_Ministry/ - acesso em 29 mar. 2020

29. China-Uzbekistan partnership to reach higher level. Xinhuanet. Disponível em: http:// www.xinhuanet.com/english/2019-10/31/c_138518582.htm - acesso em 29 mar.2020

\section{RESUMOS}

O presente artigo tem por objetivo apresentar os desafios geoeconômicos que irão se manifestar para a Ásia Central diante da recente instabilidade no mundo devido ao COVID-19. Deste modo, montamos um panorama acerca da situação pandêmica na região, e apontamos os principais elementos que funcionam como vetores geoeconômicos centro-asiáticos assim como os impactos que eles sofreram diante da recente crise mundial.

Cet article présente les enjeux géoéconomiques de l'Asie Centrale à la suite de l'instabilité mondiale provoquée par la Covid-19. Pour cela, on a ébauché un panorama de la situation pandémique dans la région, ainsi qu'on a identifié les principaux vecteurs géoéconomiques et ses enjeux devant la crise globale.

This article aims to present the geoeconomic challenges in Central Asia face to the global instability caused by Covid-19. In this way, I provided an overview of the pandemics situation in that region, as well as the recognition of the main geoeconomic factors and its challenges vis-àvis the world crisis.

Este artículo tiene como objetivo presentar los desafíos geoeconómicos que se hace manifestado para Asia Central ante la reciente inestabilidad en el mundo debido al COVID-19. De este modo, presentamo un panorama sobre la situación pandémica en la región, y apuntamos los principales elementos que funcionan como vectores geoeconómicos centroamericanos así como los impactos que ellos sufrieron ante la reciente crisis mundial. 
ÍNDICE

Palabras claves: Geografía; geopolítica; Geoeconomía; Asia Central; región Palavras-chave: Geografia; Geopolítica; Geoeconomia; Ásia Central; região. Mots-clés: géographie; géopolitique; géoéconomie; Asie centrale; région.

Keywords: geography; geopolitics; geoeconomy; Central Asia; region

\section{AUTOR}

JONATHAN CHRISTIAN DIAS DOS SANTOS

Mestrando no Programa de Pós-Graduação em Geografia da UFRRJ. Email: jonathan_christian95@hotmail.com 